\title{
En época de poshumanismos, una propuesta siempre actual: el personalismo
}

In an Age of Post-Humanism, An Unfailing Proposal: Personalism

Sergio Alejandro González*

\section{¿Qué entendemos por cultura poshumanista?}

Sin intención de hacer un racconto histórico, nos gustaría destacar algunos momentos fundamentales que dieron génesis a la cultura denominada poshumanista, que es necesario comprender mínimamente para abordar después nuestra propuesta. Para ello, nos basaremos en algunos conceptos compartidos por Massimo Borghesi, en su paso por nuestro país, la Argentina.

A partir de los años 70 la cultura europea - también la norteamericana, que llega mucho a América Latina- es una cultura poshumanista, es decir, una cultura que no tiene al hombre en el centro de la realidad, sino que considera que las estructuras económicas, sociales, lingüísticas son el verdadero fundamento de las cosas.

Según esa mirada, no son los hombres los que hacen la historia, sino que son las estructuras las que condicionan a los hombres. Esta dirección se llama "estructuralismo" y tuvo un peso enorme en toda la cultura europea a partir de los años 70 . El estructuralismo es una corriente fuertemente abstracta, que interrumpe la relación del hombre con la realidad, por un lado, y con su existencia, por el otro. Nace en Francia y toma el lugar del existencialismo que, durante los 50 y

* Profesor de Filosofía, licenciado en Ciencias de la Educación, magíster en Humanidades y Ciencias por la UNVM y delegado del Instituto argentino "Jacques Maritain", Filial Río Cuarto. 
los 60 fue la corriente más importante en ese país. El existencialismo pone en evidencia el problema de la existencia, de los dramas, de la angustia: la existencia es el problema fundamental de la vida. A partir de los años 70, en cambio, la existencia no existe más. Existe solo la estructura, algo impersonal. Desde el punto de vista del estructuralismo, no es importante quién eres, sino tu lugar en la sociedad: burgués o proletario. Quién eres, nombre y apellido, no me interesa; lo que deseas, tus angustias, tu deseo de felicidad, nada de esto me interesa. El estructuralismo destruye, en definitiva, el sentido religioso del hombre.

Uno de los teóricos más conocidos en esta corriente, Michel Foucault, declara explícitamente que el tiempo del hombre ha terminado: si Dios ha muerto, el hombre muere con Dios, porque el hombre no puede pretender ser el centro de la naturaleza y de la historia si Dios no existe. Este planteamiento vuelve imposible una educación humanista, al menos aquella compuesta por los valores greco-romanos, judeo-cristianos, de los cuales somos deudores. No tiene sentido hablar de la educación del hombre si el hombre no tiene ninguna centralidad. Sería un engaño decir a nuestros alumnos que estamos ocupados en su educación cuando lo único que importaría, según esa escuela filosófica, son las estructuras sociales, jurídicas y políticas en las cuales están inmersos.

Todo esto fue confirmado por uno de los grandes estudiosos contemporáneos, Tzvetan Todorov, protagonista de la fase estructuralista. En uno de sus últimos libros, La literatura en peligro, él dice que el estructuralismo, método de estudio no solo en la universidad sino también en los institutos y en las escuelas francesas, es el principal responsable de la crisis de los estudios humanísticos en Francia en ese momento. Así como el método estructuralista impide la relación con la realidad y elimina el método existencial, elimina también el método narrativo.

No queremos con este pequeño análisis caer en el juego dialéctico y maniqueo, que los estructuralistas son los malos, y los humanistas somos los buenos. No, lo que queremos expresar es que debemos ser coherentes y sobre todo honestos cuando nos dirijamos a los alumnos en las aulas, no utilizando conceptos humanistas para defender ideologías poshumanistas. 


\section{La profundización del post-humanismo: el transhumanismo}

Julián Huxley, quien fuera el primer director de la UNESCO, miembro de la First Humanist Society of New Cork y presidente de la Internacional Humanist and Ethical Union, introdujo el concepto contemporáneo de "transhumanismo" en 1957, al señalar:

la especie humana puede, si lo desea, trascenderse - no sólo esporádicamente, un individuo aquí de una manera, otro allí de otra forma - sino en su totalidad, como humanidad. Necesitamos un nombre para esta nueva creencia. Quizás Transhumanismo pueda servir: el hombre sigue siendo hombre, pero trascendiéndose, a través de la realización de nuevas posibilidades.

Por otro lado, Nick Bostrom, filósofo y experto en inteligencia artificial, director del Future of Humanity Institute, de la Universidad de Oxford, y presidente de la World Transhumanist Association, define el transhumanismo como:

un movimiento cultural, intelectual y científico, que afirma el deber moral de mejorar la capacidad física y cognitiva de la especie humana y de aplicar al hombre nuevas tecnologías, de manera que se puedan eliminar los aspectos no deseados e innecesarios de la condición humana como el sufrimiento, la enfermedad, el envejecimiento e incluso, el ser mortales.

El término "transhumanismo" está íntimamente vinculado con esta crítica posmoderna al humanismo, encarnada por el posthumanismo. Si bien, en este sentido, todos los transhumanistas podrían ser considerados posthumanistas, no todos los posthumanistas podrían ser considerados transhumanistas, ya que éstos llevan al extremo la cultura propuesta por aquellos.

Ya en 1923 Haldane publicaba el ensayo Daedalus; or, Science and the future, texto en el que promueve la aplicación de la genética y otras ciencias recientes a la biología humana. Si observamos las últimas investigaciones científicas en biotecnología, advertiremos que esa propuesta de principio del siglo XX está a la orden del día en los grandes laboratorios multinacionales de hoy. Lo peligroso de todo esto es que la manipulación embrionaria, por ejemplo, no admite límite ético-moral para estos centros de investigación que experimen- 
$\tan$ con seres humanos (aunque se encuentren en su etapa embrionaria).

Respecto de sus objetivos, algunos de los teóricos transhumanistas, como por ejemplo los cultores del extropianismo, sostienen que la aplicación de la tecnología debe enfocarse en mejoras puntuales de tipo individual. Otros, en cambio, como por ejemplo los integrantes de la World Transhumanist Association, pretenden aplicar la ciencia y la tecnología para reducir la incidencia de enfermedades, la discapacidad y la malnutrición del mundo. Está claro que ninguno de nosotros se debería oponer a que la ciencia siga avanzando en el descubrimiento de nuevos tratamientos biotecnológicos, que disminuyan o atenúen los impactos que hoy tienen sobre la población mundial las enfermedades, discapacidades y todo lo que tiene que ver con la desnutrición. Nuestra objeción estará planteada en la necesidad de que se acuerden límites éticos-morales para que no se atropelle ninguna dignidad humana, sea esta de Europa, América o África, ya que el fin nunca debería justificar los medios.

De esta manera, la cultura transhumanista fomenta la convergencia de tecnologías como la nanotecnología, la biotecnología, la tecnología de la información y la ciencia cognitiva, es decir, las denominadas con la sigla NBIC. Aunque podemos llegar a compartir el avance tecnocientífico en estas cuatro áreas del conocimiento mencionadas, no nos parece prudente que las mismas, en su avance exponencial, no delimiten sus investigaciones, ya que sostenemos que todo lo cientificamente posible no siempre será éticamente aceptable.

Siguiendo a nuestro autor de referencia, en lo que respecta a las libertades básicas que sostiene este movimiento, podemos resumirlas en tres:

- Libertad morfológica: la condición humana no implica estar sujeto a las limitaciones impuestas por una estructura biológica natural (esta a su vez se subdivide en libertad intracorpórea, intercorpórea y transcorpórea).

- Libertad reproductiva: el ser humano tiene derecho a reproducirse de la manera que lo desee, utilizando para ello todas las tecnologías de la reproducción asistida que tenga a su disposición.

- Libertad cognitiva: el ser humano debe disponer de plena libertad para alcanzar la meta de plena expansión de la conciencia. Se vin- 
cula a la poscorporeidad. Señala el pasaje del soporte somático a otro, expandiendo las posibilidades de desmaterialización. En este tema se suele utilizar la subdivisión entre humanos Cyborg y humanos Fyborg.

\section{No olvidemos los principios y valores del humanismo}

El transhumanismo sufre críticas de fondo que provienen principalmente de dos vertientes. Por una parte, desde una aproximación práctica, que cuestiona las metas transhumanistas; por otra, desde una aproximación ética, que cuestiona los principios morales. Sin embargo, estos dos enfoques con frecuencia convergen y se superponen, dada la complejidad de los fundamentos epistemológicos en juego.

El Center for Genetics and Society es una organización que se opone a los objetivos transhumanistas, en particular para combatir las teorías que puedan conllevar modificaciones transgeneracionales que puedan afectar la biología humana, como por ejemplo la clonación. Por otro lado, el Worldwatch Institute es otro detractor de los organismos genéticamente modificados y ha señalado su preocupación ante la posibilidad de aplicar la tecnología genética a los seres humanos.

Con el fin de ir concluyendo con esta propuesta, queremos resumir las objeciones que nuestro autor de referencia expone contra la ideología poshumanista, desde los principios y valores humanistas. Las mismas, a nuestro criterio, las podemos reunir en cuatro:

Objeciones antropológicas: distintas corrientes científico-filosóficas alzan su voz en contra de esta posición transhumanista. Dichas voces provienen de un amplio espectro ideológico, que va desde el neoaristotelismo de Francis Fukuyama al neomarxismo de Jurgen Habermas. La condición de "persona" ya no se adscribe únicamente al ser humano, sino que se puede atribuir a otros entes que hipotéticamente puedan llegar a tener conciencia de sí mismos, como por ejemplo los grandes simios; inclusive, algunos transhumanistas radicales pretenden extender la condición de persona a los sistemas de inteligencia artificial que se pudiesen desarrollar en el futuro. Nosotros sostenemos que el sujeto no es persona por el hecho de poder desplegar sus potencialidades, sino que puede llegar a desplegar sus potencias justamente porque es persona. 
Objeciones éticas: los transhumanistas sostienen que el mayor de los riesgos éticos sería no usar la ingeniería genética, porque las tecnologías actuales ya amenazan el entorno y porque un gran número de personas muere todos los años por causas que podrían ser solucionables con una mayor aplicación de innovación tecnológica. Ellos entienden que, como los potenciales beneficios superan los potenciales riesgos, el imperativo moral es empezar a usar estas tecnologías tan pronto como sea posible. Por otro lado, desde el ámbito de la bioética se destaca la airada crítica de voces como las de León Kass, Edmund Pellegrino o Michael Sandel, quienes exponen sus objeciones basadas en la constitución y dignidad intrínseca de toda vida humana, que subyace desde el mismo instante de su concepción hasta su muerte natural.

Objeciones biológicas: el transhumanismo adscribe a la concepción instrumental del cuerpo humano entendido como mero vehículo. El miedo a la muerte y la incapacidad de abrazar la trascendencia alienta a intentar superar la condición mortal de la humanidad a través de la técnica. Ejemplo de ello es el deseo de transferir la conciencia a algún tipo de dispositivo electrónico. En este sentido, sostenemos que las leyes biológicas son irrefutables y que la condición humana está determinada a una finitud material, de la misma manera que el resto de los seres vivos de este planeta.

Objeciones sociales: si se siguen los postulados transhumanistas al pie de la letra, aplicando la tecnología genética actual se podría terminar creando una sociedad aún más segmentada, con algunas clases sociales que estarían en condiciones de tener un acceso a los nuevos desarrollos biotecnológicos, y otras clases que no podrían disfrutar de las supuestas virtudes de dichos procedimientos. A este respecto, Francis Fukuyama considera estas ideas como una de las más peligrosas de mundo en este momento, en función de que sus postulados son opuestos a la naturaleza humana. El transhumanismo atenta contra el principio de igualdad cuando pretende alterar la esencia humana, socavando de esta manera los fundamentos mismos de la sociedad democrática.

\section{Conclusiones}

Hemos expuesto los conceptos más representativos de la cultura posthumanista en general, y los del transhumanismo en particular. El fin fue presentarlos brevemente para que el lector advierta de sus 
riesgos, si los miramos desde los principios y valores del humanismo. Es cierto también que no nos fue muy bien como humanidad, cuando hemos demonizado aquellas corrientes de pensamiento que no entendían la realidad como nosotros. Por tal motivo llegando al final de nuestra ponencia, queremos dejar en claro que la idea substancial es poner en la mesa del diálogo interdisciplinario los argumentos racionales, que permitan generar el debate epistémico en los ámbitos científico-filosóficos que sean necesarios.

Ahora bien, por un lado, la cuestión educativa se está convirtiendo, a nivel mundial, en un problema político. Es lo que sucede en Europa, en Estados Unidos, en China. También es así en América Latina. Nos damos cuenta de que las generaciones actuales no egresan de las instituciones educativas con una formación cultural y humana completa, después de haber transitado la formación escolar obligatoria y la superior también. Podemos decir que la escuela de hoy, en general, no educa, porque no logra introducir a los estudiantes en una relación crítica y positiva con la realidad. La cultura adquirida en la escuela, en definitiva, no logra convertirse en un criterio de juicio.

Por otro lado, los tiempos actuales poshumanistas proponen absolutizar los subjetivismos: al sujeto en sí y para sí. Una propuesta siempre vigente es aquella que se centra en el ser persona de la subjetividad humana, pero no acentuando al extremo el sujeto, sino situándolo frente al resto de los objetos que lo rodean y erigiéndolo en el gran administrador sí, pero no definitivamente en el dueño absoluto de todo su entorno.

Por último, motivamos a todos aquellos educadores que, por vocación, han respondido el llamado de acompañar a otros semejantes en este trayecto formativo que es la vida humana, no abandonen tan noble tarea, creyendo que están solos en la Aldea Global, intentando defender aquellos principios y valores humanistas que nos dignifican, ante todo, como personas. 